\title{
Effects of ankle balance taping with kinesiology tape for a patient with chronic ankle instability
}

\author{
Byeong-Jo Kim, PhD, PT ${ }^{1)}$, Jung-Hoon Lee, PhD, PT ${ }^{1}{ }^{*}$, Chang-Tae Kim, DBA ${ }^{2)}$, \\ Sun-Min LeE, PhD, $\mathrm{PT}^{3)}$ \\ 1) Department of Physical Therapy, College of Nursing and Healthcare Sciences, Dong-Eui University: \\ 176 Eomgwangno, Busanjin-gu, Busan 614-714, Republic of Korea \\ 2) Department of Healthcare Management, College of Nursing and Healthcare Sciences, Dong-Eui \\ University, Republic of Korea \\ 3) Department of Occupational Therapy, College of Rehabilitation Science, Daegu University, Republic \\ of Korea
}

\begin{abstract}
Purpose] To report the effects of ankle balance taping for a patient with chronic ankle instability (CAI). [Subject] A 33-year-old man with a 10 year history of chronic ankle stability. [Methods] ABT with kinesiology tape was performed for 2 months (average, $16 \mathrm{~h} /$ day) around the right ankle. [Results] At the end of two months, no ankle instability was noted when ascending and descending the stairs, jumping, turning, operating the pedals while driving, and lifting heavy objects. [Conclusion] The repeated use of kinesiology tape in ankle balance taping may be an effective treatment for recovering the ankle stability of patients with chronic ankle instability.

Key words: Cumberland Ankle Instability Tool, Elastic therapeutic tape, Kinesio taping
\end{abstract}

(This article was submitted Feb. 19, 2015, and was accepted Mar. 17, 2015)

\section{INTRODUCTION}

Ankle injuries are common in sports-related and recreational activities ${ }^{1)}$, and $85 \%$ of these injuries are sprains ${ }^{2)}$. More than $40 \%$ of patients with ankle sprains may experience swaying of the ankle without any structural limitations or ankle instability ${ }^{3}$, which may eventually result in chronic ankle instability (CAI). Individuals with CAI have injuryrelated fear and functional deficits when performing activities of sports and daily living ${ }^{4,5}$.

We report on the efficacy of ankle balance taping (ABT) with kinesiology tape for the recovery of ankle stability in a patient with CAI.

\section{SUBJECT AND METHODS}

A 33-year-old man had chronic instability of the right ankle for 10 years after he experienced right lateral ankle sprains. He reported ankle instability when ascending and descending the stairs, jumping, turning, operating the pedals while driving, and lifting heavy objects. The patient provided his written informed consent, and the study was performed in accordance with the ethical principles of the Declaration of Helsinki.

*Corresponding author. Jung-Hoon Lee (E-mail: dreampt@ hanmail.net)

(C2015 The Society of Physical Therapy Science. Published by IPEC Inc. This is an open-access article distributed under the terms of the Creative Commons Attribution Non-Commercial No Derivatives (by-ncnd) License $<$ http://creativecommons.org/licenses/by-nc-nd/3.0/> .
The Cumberland Ankle Instability Tool (CAIT) questionnaire, which has 9 items and a 30-point scale for measuring self-reported functional ankle deficits, was completed by the patient. The CAIT is a valid and reliable tool that is indicative of perceived ankle instability ${ }^{6}$. Scores of $\leq 27$ indicate functional ankle instability ${ }^{6}$, and the CAIT score for the right ankle in the present case was 10/30.

To assess static balance, we used the Balance Error Scoring System (BESS), which is a portable, objective, and inexpensive method for assessing static postural stability ${ }^{7}$. It consists of performing a double-leg stance with the hands placed on the iliac crest; single-leg stance with the hands placed on the iliac crest (standing on the right leg); and a tandem stance with the hands placed on the iliac crest (right foot placed behind the left foot), on firm and foam surfaces with the eyes closed. Errors in this system include opening the eyes; lifting the hands off the iliac crests; failing to return to the starting position within $5 \mathrm{~s}$; stepping, stumbling, or falling out of position; moving the hip into $>30^{\circ}$ of abduction; and lifting the forefoot or heel ${ }^{7}$. A score of 1 is logged for each error, and the total BESS score for each position is 10. The patient's error scores were as follows: the double-leg stance on firm and foam surfaces, $0 / 10$ and 0/10; single-leg stance on firm and foam surfaces, $3 / 10$ and 10/10; and tandem stance on firm and foam surfaces, 5/10 and 10/10, respectively.

Dynamic balance was assessed using the Star Excursion Balance Test (SEBT), which is a quick cost-effective method of assessing dynamic postural control. The maximum reach distances were measured in three directions (anterior, posteromedial, and posterolateral) of the left leg while the patient maintained a right-leg stance at the center of the three 
directions ${ }^{8)}$. The reach distances of the anterior, posteromedial, and posterolateral directions were $56.3 \mathrm{~cm}, 64.5 \mathrm{~cm}$, and $63.5 \mathrm{~cm}$, respectively.

In addition, the active range of motion of the ankle was measured using a universal goniometer. Initially, the range of motion for inversion, eversion, dorsiflexion, and plantarflexion of the right ankle were $15 / 45^{\circ}, 15 / 20^{\circ}, 20 / 30^{\circ}$, and $60 / 60^{\circ}$, respectively.

We performed ABT using kinesiology tape (BB Tape, WETAPE Inc., Seoul, Korea) around the ankle for 2 months (average, $16 \mathrm{~h}$ /day) for recovery of ankle stability. The ABT method consists of four steps, which involve stretching the kinesiology tape to approximately $30-40 \%$ of the original length. First, to enhance posterior talar glide, the tape was applied from the talus to the calcaneus in a slightly dorsiflexed position (Fig. 1A). Second, to enhance ankle eversion, the tape was applied above the lateral malleolus over the medial calcaneus to the inside of the instep in an everted position (Fig. 1B). Third, to enhance ankle inversion, the tape was applied above the medial malleolus over the lateral calcaneus to the outside of the instep in an inverted position (Fig. 1C). Fourth, to further enhance ankle eversion, the third step was repeated (Fig. 1D-E). Fifth, to further enhance the posterior talar glide, the first step was repeated (Fig. 1F). To prevent any interruption in therapy because of skin problems, care was taken to avoid stretching the end and starting points of the tape at every stage of the application ${ }^{9}$. ABT was performed repeatedly, every day, after removal of the previous tape even if there was no itching. No other treatments were used for treating CAI.

\section{RESULTS}

After 2 months of taping, the error scores for the singleleg stance on firm and foam surfaces decreased from $3 / 10$ to $0 / 10$ and from $10 / 10$ to $3 / 10$, respectively. The error scores for the tandem stance on firm and foam surfaces also decreased from $5 / 10$ to $0 / 10$ and from $10 / 10$ to $0 / 10$, respectively. The reach distances of the anterior, posteromedial, and posterolateral directions increased from $56.3 \mathrm{~cm}$ to $68 \mathrm{~cm}$, from $64.5 \mathrm{~cm}$ to $90 \mathrm{~cm}$, and from $63.5 \mathrm{~cm}$ to $88.5 \mathrm{~cm}$, respectively. The range of motion for inversion, eversion, dorsiflexion, and plantarflexion increased from $15 / 45^{\circ}$ to $42 / 45^{\circ}$, from $15 / 20^{\circ}$ to $20 / 20^{\circ}$, from $20 / 30^{\circ}$ to $30 / 30^{\circ}$, and from $60 / 60^{\circ}$ to $58 / 60^{\circ}$, respectively. Furthermore, the CAIT score increased from $10 / 30$ to $28 / 30$. The patient no longer experienced ankle instability when ascending and descending the stairs, jumping, turning, operating the pedals while driving, and lifting heavy objects.

\section{DISCUSSION}

This case showed that the repeated application of kinesiology tape in ABT over 2 months increased the range of motion of the ankle. Kinesiology tape may stimulate cutaneous mechanoreceptors ${ }^{10)}$. In accordance with the counterirritant theory, the excitement of the mechanoreceptors induces the release of encephalin, which inhibits the transmission of nociceptive signals ${ }^{11)}$. Therefore, the increase in the threshold of pain transmitted by receptors of the ankle joint due to ABT may have increased the ankle range of motion in the

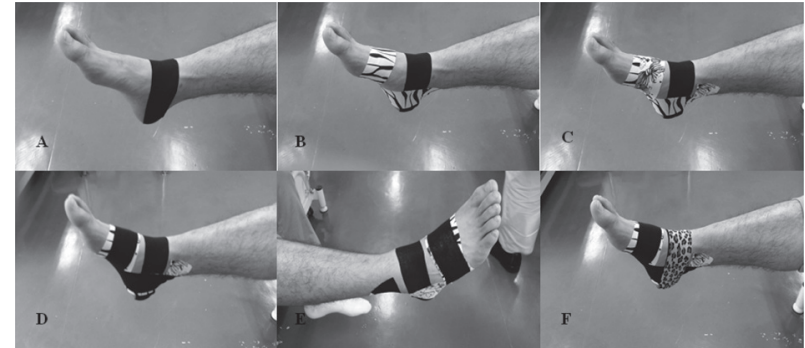

Fig. 1. Ankle balance taping using kinesiology tape

present case.

In the early stages of ankle recovery, movement of the weakened joints is limited by the lack of power to overcome the decreased elasticity of the tape, and the ankle joint is hence supported. Thus, the recurrence of ankle sprains during activities of sports and daily living are prevented.

Moreover, kinesiology tape may improve the joint position sense ${ }^{12)}$ and support the joint structure ${ }^{13)}$. The activation of proprioceptors as a result of the application of kinesiology tape around the ankle joint ${ }^{12)}$ increases the ankle joint position sense, which maintains the neutral ankle position. Thus, the increased ankle stability increased the reach distances in the SEBT test, decreased the error scores in the BESS test, and improved the CAIT score. However, additional research on the clinical efficacy of ABT using kinesiology tape involving more patients with $\mathrm{CAI}$ is required.

\section{REFERENCES}

1) Bell DR, Guskiewicz KM, Clark MA, et al.: Systematic review of the balance error scoring system. Sports Health, 2011, 3: 287-295. [Medline] [CrossRef]

2) Liu SH, Nguyen TM: Ankle sprains and other soft tissue injuries. Curr Opin Rheumatol, 1999, 11: 132-137. [Medline] [CrossRef]

3) Sekir U, Yildiz Y, Hazneci B, et al.: Effect of isokinetic training on strength, functionality and proprioception in athletes with functional ankle instability. Knee Surg Sports Traumatol Arthrosc, 2007, 15: 654-664. [Medline] [CrossRef]

4) Arnold BL, Wright CJ, Ross SE: Functional ankle instability and healthrelated quality of life. J Athl Train, 2011, 46: 634-641. [Medline]

5) Hale SA, Hertel J: Reliability and sensitivity of the Foot and Ankle Disability Index in subjects with chronic ankle instability. J Athl Train, 2005, 40: 35-40. [Medline]

6) Hiller CE, Refshauge KM, Bundy AC, et al.: The Cumberland ankle instability tool: a report of validity and reliability testing. Arch Phys Med Rehabil, 2006, 87: 1235-1241. [Medline] [CrossRef]

7) Riemann BL, Guskiewicz KM, Shields EW: Relationship between clinical and forceplate measures of postural stability. J Sport Rehabil, 1999, 8: $71-82$.

8) Coughlan GF, Fullam K, Delahunt E, et al.: A comparison between performance on selected directions of the star excursion balance test and the $\mathrm{Y}$ balance test. J Ath1 Train, 2012, 47: 366-371. [Medline]

9) Kim BJ, Lee JH: Effects of scapula-upward taping using kinesiology tape in a patient with shoulder pain caused by scapular downward rotation. $\mathrm{J}$ Phys Ther Sci, 2015, 27: 547-548. [Medline] [CrossRef]

10) Yamashiro K, Sato D, Yoshida $T$, et al.: The effect of taping along forearm on long-latency somatosensory evoked potentials (SEPs): an ERP study. Br J Sports Med, 2011, 45: A9. [CrossRef]

11) Lundy-Ekman L: Neuroscience fundamentals for rehabilitation, 3rd ed. St. Louis: Saunders Elsevier, 2007.

12) Murray H, Husk L: Effect of kinesio taping on proprioception in the ankle. J Orthop Sports Phys Ther, 2001, 31: A-37.

13) Kim BJ, Lee JH: Efficacy of kinesiology taping for recovery from occupational wrist disorders experienced by a physical therapist. J Phys Ther Sci, 2014, 26: 941-943. [Medline] [CrossRef] 